\title{
LESS IS MORE OR MORE IS MORE? REVISITING UNIVERSALITY OF HUMAN RIGHTS
}

\author{
Tanel Kerikmäe \& Katrin Nyman-Metcalf ${ }^{1}$ \\ Talinn Law School, Tallinn University of Technology, Estonia \\ email: tanel.kerikmae@ttu.ee; katrin.nyman-metcalf@ttu.ee
}

KERIKMÄE, Tanel, NYMAN-METCALF, Katrin. Less is More or More is More? Revisiting Universality of Human Rights. International and Comparative Law Review, 2012, Vol. 12., No. 1, pp. 39-56. DOI: 10.1515/iclr-2016-0077.

\begin{abstract}
Human rights are much talked about and much written about, in academic legal literature as well as in political and other social sciences and the general political debate. Indeed, they are so often referred to and used as a basis for claims of various kinds that there may be a risk of certain "inflation" in that so much is said to be a human right that the notion loses its essential meaning. This article argues that the universality of basic human rights is one of the values of the concept of rights. The rights and the understanding and interpretation of rights may have to be purist. This may be the way universal human rights as a concept can survive at all. In the modern world there are different trends that to some extent conflict, like the trend of globalisation but also the re- emphasising in different parts of the world of traditional values, whether from a religious background or something else. It appears that the basic dogma of human rights - which has also been called the first universal ideology - that it is the individual and her rights and freedoms that should always be in the centre of any human rights discourse, is abandoned all the more often as the central principle. Instead the banner of human rights is used for various political and economic aims
\end{abstract}

Keywords: universality, human rights, legitimacy, interpretation, inflation of rights, different cultural context

\section{Introduction}

Human rights are much talked about and much written about, in academic legal literature as well as in political and other social sciences and the general political debate. Indeed, they are so often referred to and used as a basis for

1 Prof. Dr. Tanel Kerikmäe \& Prof. Dr. Katrin Nyman-Metcalf. Talinn Law School, Tallinn University of Technology, Estonia. Emails: tanel.kerikmae@ttu.ee; katrin.nyman-metcalf@ ttu.ee 
claims of various kinds that there may be a risk of certain "inflation" in that so much is said to be a human right that the notion loses its essential meaning. Another danger of the expansive look on human rights is that the idea of the universality of rights, which is one of the philosophical underpinnings of the phenomena, is lost. May it be so, that if more and more is said to be a human right, in fact the importance of the rights is instead reduced? Perhaps fewer but stronger rights can better serve the original purpose of universal human rights? On the other hand, it is possible that the notion of human rights is expandable and adding more to it does not detract from the previously existing rights.

This article argues that the universality of basic human rights is one of the values of the concept of rights. There may of course be (and there should be!) many other rights than basic human rights granted to individuals through national law or international agreements, but these are different from universal human rights. To maintain universality of rights, the expansion of what is regarded as being a basic human right may need to be slowed down. This is not to say that conventions should not be interpreted with certain flexibility, as otherwise they would quickly lose their usefulness. However, there should be a limit to how widely a right is interpreted so as not to erode its original meaning totally.

Maybe it is so that fewer rights but stronger ones which furthermore are really universal actually could mean more rights? The rights and the understanding and interpretation of rights may have to be purist. This may be the way universal human rights as a concept can survive at all. In the modern world there are different trends that to some extent conflict, like the trend of globalisation but also the re-emphasising in different parts of the world of traditional values, whether from a religious background or something else.

The Arab world in the Jasmine revolutions rejects Western assistance and influence, but contrary to fears, the revolutions overthrowing old allies of the West have not mainly been revolutions of the Muslim brotherhood and similar fundamentalist groups. There is an assertion of own values, but the core of these do contain universal values. If human rights are seen as universal they can also be used in different contexts. Their origin may be European or "Western" but the core of them is universal, the core rights can apply anywhere and to anyone - if the core can be distilled.

It is also conceivable that if such a core exists, humanitarian intervention to protect this core could be more easily applicable than in a situation where the question for what an intervention may take place is even difficult to answer theoretically. In practice, the temptation to use the label of humanitarian interventions for other and much more sinister intrusions into other states will remain, but a clear concept of what really is a universal human right that should be protected everywhere may make the yardstick with which interventions are measured somewhat clearer. 
It appears that the basic dogma of human rights - which has also been called the first universal ideology - that it is the individual and her rights and freedoms that should always be in the centre of any human rights discourse, is abandoned all the more often as the central principle. Instead the banner of human rights is used for various political and economic aims.

Human rights can be approached from different perspectives.

1. As an attack on the concept of State sovereignty as traditionally conceived;

2. As a goal-setting agenda for global policy;

3. As a standard for assessing behaviour and therefore for judging political legitimacy; or as

4. A movement of concerned private individuals and groups that transcend political boundaries and which is an increasingly significant factor in international relations. $^{2}$

Application of human rights may be seen as interference in the sovereignty of states. In a sense, any imposition from outside on values on a state could in a strict interpretation be seen as interference. The idea of rights is to positively influence behaviour and change it when needed. However, the idea of universal human rights presumes that they are not per se seen as interventions. At the same time, the human rights ideology lives a life of its own - it produces standards that go further than basic human rights and basic principles. This may be a form of superior law as it directly protects individuals and is ideally linked to both positive law and natural law (a new thought in legal philosophy and linked also to new technological and similar developments).

\section{The development of human rights - a very brief overview}

There is abundant literature on human rights; what they are, where to find them and how they developed. There would be little benefit in repeating this discussion in this article as the reader is presumed to have the basic knowledge against which to evaluate the argument of the article. Thus a very brief setting of the stage for the discussion is all that is made here. ${ }^{3}$

In human rights discussions a reference to different generations of human rights is often used. Although this division of rights into generations is debated ${ }^{4}$,

2 R.P. Claude and B. H. Weston (eds.), Human Rights in the World Community. Issues and Action: University of Pennsylvania Press, 1989

3 Among the very many sources, for recent books with different viewpoints, see M. Freeman, Human Rights: an interdisciplinary approach: Cambridge University Press, 2011; D. Moeckli, S. Shah, S.Sivakumaran (eds.) International Human Rights Law: Oxford University Press, 2010; A. Vincent, The Politics of Human Rights: Oxford University Press, 2010

4 Anderson finds that the talk of generations may distract from the responsibility to react to human suffering where-ever it arises rather than focusing on theoretical differences between types of rights. G.W.Anderson, "Human Rights and the Global South"(Chapter 
it is a useful tool to show the difference between categories of rights, including for example how universally accepted they are and whether they are primarily individual (the first two generations) or collective (the third generation and the fourth one, if that exists). The first generation rights are civil and political rights, which are also the most universally accepted although also here with different interpretations. The second one consists of social and cultural rights. The third generation encompasses collective rights like the right to development, peace and a clean environment. The possible existence of a fourth generation of rights, which would be rights related to scientific and technological development, is much less widely accepted than the first generations. ${ }^{5}$ Rights that belong to the third generation, especially the right to a clean environment, are the focus of much attention in recent years, as an element of the environmental protection movement. This has made people more aware of the rights discourse also as regards the later generations of rights.

This article does not go into the debate of colonialism and whether the human rights are really universal or instead a Western invention. This discussion has evolved over the years as colonialism as such has receded in time, but now some authors for example point to the need to alleviate human suffering as something that should be central in the rights discourse rather than the content of accepted rights. ${ }^{6}$ One difference in what Anderson calls a Southern view on rights is that it does not focus on institutions, international protection mechanisms and the like but more looks at rights outside such traditional institutional architecture. ${ }^{7}$ Linking rights to development can also be used to avoid (or try to avoid) attention to human rights abuses through referring to the hard economic situation of a country. ${ }^{8}$

The Vienna World Conference on Human Rights in 1993 witnessed the most serious challenge to the idea of the universality of human rights norms and standards since the end of the Second World War. In the end, this challenge was deflected through the efforts of Western delegates in the official conference drafting committee, who, acting under pressure from human rights nongovernmental organisations, had the statement, "The universal nature of these rights and freedoms is beyond question", adopted by consensus and included in the final draft of the Vienna Declaration and Programme of Action which has a status of declaratory resolution of the United Nations General Assembly. The

17) in T. Campbell, K.D. Ewing and A. Tomkins (eds.), The Legal Protection of Human Rights. Sceptical Essays: Oxford University Press, 2011, pp 347-364.

5 C. Ovey and R.C.A. White Jacobs \& White, The European Convention on Human Rights 4th edition: Oxford University Press, 2006, pp 5-6.

6 Anderson, op.cit., p 356.

7 Anderson, op.cit., p 357.

8 Something Ethiopia appears to get away with rather often. See "The compass fails", The Economist 17 September 2011. 
main idea is that human rights must prevail over cultural relativism and regional fragmentation. ${ }^{9}$

Whereas the Universal Declaration of Human Rights of 1948 still proceeded from a homogenous and universal concept of human rights, subsequent debates have focussed on the priority of different cultures, economies and regions. This debate led to a bifurcation of human rights culminating in the adoption of the two UN Covenants in 1966, one dealing with economic, social and cultural rights and the other with civil and political rights. This separation can be explained also with notion that the ability of States fully to grant economic, social and cultural rights depends in part on development in certain State. It is sometimes argued ${ }^{10}$ that economic and social rights cannot be rights at all, because "rights" implies something in respect of which legal claims can be brought, and economic and social rights are not justiciable. Also, they are imprecise in content (such as freedom from hunger and the right to adequate food) and can be treated more like aspirations. This argument is tested by theory that a right is just as much right if its implementation requires positive steps rather than negative abstinence. The concept of positive duties is increasingly becoming part of the normative requirements of civil and political rights.

\section{Civil and political versus economic and social rights, individual rights versus collective rights}

On the regional level, Europe and America gave priority to civil and political rights; instruments on second generation of rights were drafted somewhat later. The European Convention on Human Rights of 1950 was followed by the European social Charter in 1961, a much weaker instrument. According to Schreuer ${ }^{11}$ it is ironic that Western Europe, the region with the highest social standards domestically, has regarded the international protection of these rights with some diffidence. The American Convention on Human Rights of 1969 was followed by an Additional Protocol in the Area of Economic, Social and Cultural Rights in 1988. The African Charter embodies both categories of human rights and additionally collective rights. Thus, one can say that social, cultural and economic rights are not legal rights because of a lack of judicial machinery (in the European region for example). Ubi remedium ubi ius is the Roman maxim which should prevail over the argument of certain authors ${ }^{12}$, that legal enforcement is not essential to the existence of rights.

9 See Articles 1,5,32 and 37 of the Declaration.

10 R. Higgins, Problems and Process. International Law and How We Use It: Clarendon Press, 1994, pp. 99-100.

11 Ch. Schreuer, "Regionalism v. Universalism", European Journal of International Law, Vol. 6 No. 3: European University Institute, Florence, 1995, p.485.

12 J. W. Nickel, Making Sense of Human Rights. Philosophical Reflections on the Universal Declaration of Human Rights:University of California Press , Berkeley and Los Angeles, 1987, p.35. 
Scheinin, agreeing that economic and social rights are legally weak because of the wording of these provisions and by the relatively weak international monitoring mechanisms, however argues that economic and social rights are "an essential part of the normative international code of human rights"13 indicating that the justiciability of these rights has developed through the complaint procedures under treaties on civil and political rights, especially in regard to caselaw under Art. 26 of the CCPR and Art. 6(1) of the ECHR. ${ }^{14}$ It seems that the separation of "social dimensions" of civil and political rights makes the theoretical situation of economic and social rights even worse. Losing their normative independence, they lose their practical existence. Nevertheless, as the "generations" of human rights are allegedly artificial (human rights law is in a complex network of provisions of criminal and civil law), the practice can change the theoretical framework (by assumption that action comes first and theory later).

Many controversies in the field of human rights are between individual and collective rights as third generation of rights or "solidarity rights" (self-determination, clean environment etc.). They may even be in conflict i.e. the enjoyment of collective rights may restrict the enjoyment of individual rights and vice versa. The only way to find a solution for this antinomy is accommodation (no interdependence). The debate concerning so-called "people's rights" is one of the results of a wider ideological clash between socialist economical systems, which emphasize the interests of the State, the group, the tribe, or the family and capital economic systems, which emphasize the interests of the individual. The danger seems to be in fact, that "people's rights" have created theoretical hierarchical superiority to individual rights. It is question of their relation to existing human rights. It can be said, that "people's rights" are derived from ius cogens or they are part of it. However, no actual example of that category exists. So, the justification of the collective rights seems to be somehow artificial - just to find a legal category if there is some legal point or function in having the category and if at least some examples of cases fall within this category.

Human rights are the rights of individuals, to meet the needs and purposes of individuals. But, since some needs and purposes can only be met by individuals acting together, it is necessary to recognize the right of individuals to associate together. Association always involves some restriction of members' freedom of action in relation to each other. That is why several theorists suggested the creation of collective rights, separate rights to reduce tension between individual and collective needs. Nevertheless, this separation of two types of human rights norms can make the clash even bigger.

13 M. Scheinin, "Economic and Social Rights as Legal Rights" in A. Eide, C. Crause \& A. Rosas (eds.), Economic, Social and Cultural Rights: Martinus Nijhoff Publishers, 1995, p. 41.

14 Ibid., p. 44-51. 
As Sieghart argues, the collective rights are not compatible with human rights theory only by the fact, that human rights law is created exactly to protect individuals from collectives (which, of course can have their own, collective rights): "Since those human rights are, by definition, the rights which international law ascribes to all human individuals by virtue of the fact alone that they are human individuals, they cannot of their nature belong to abstract collectivities.... Indeed, the whole purpose of ascribing "human" rights to every human being, to protect weak individuals from the strong collectivities which seek to exercise power over them, could be fatally undermined if rights of the same paramount rank where to be allowed to those very collectivities." ${ }^{15}$ Unfortunately, the practice goes its own way ${ }^{16}$, and various collective rights (like self-determination, right to peace and security and environmental rights) are recognized in the discourse of international law as "people's rights" equivalent to "human rights" despite the fact that "the life of the human being is conditioned more and more by the demands of collective life" 17 .

\section{Derogability of Rights}

Among the more traditional (especially first generation rights) there are "absolute" and "non-absolute" rights. Certain human rights may not be derogated even in times of war or public emergency threatening the nation ${ }^{18}$. Nonderogable rights can evidently be part of ius cogens.

Under the European Convention on Human Rights, the non-derogable rights are: right to life (except in cases resulting from lawful acts of war), the prohibition on torture and slavery, and non-bis-idem principle, i.e. non-retroactivity of criminal offences. ${ }^{19}$ Under the American Convention, these rights are the following: the rights to judicial personality, life and humane treatment, freedom from slavery, freedom from ex post facto laws, freedom of conscience and religion, rights of the family, to a name, of the child, nationality and participation in government. ${ }^{20}$ The universal standard is established by Article 4 of the United Nation's Civil and Political Rights Covenant. Non-derogable rights are: the rights to life and recognition as a person before the law, the freedoms of

15 P. Sieghart, "International Human Rights Law: Some Current problems" in R. Blackburn \& J. Taylor (eds.), Human Rights for the 1990s. Legal, Political and Ethical Issues: Mansell, 1991, p. 39.

16 J. Crawford, “The Rights of Peoples: "Peoples" or "Governments" in J. Crawford (ed.), The Rights of Peoples: Clarendon Press Oxford, 1992, pp. 56-57.

17 R. Cassin, "Man and the Modern State" in An Introduction to the Study of Human Rights. Based on a series of lectures delivered at King's College, London in the autumn of 1970: Europa Publications, 1970, p. 43.

18 A thorough inquiry in this field: J. Fizpatrick, Human Rights in Crisis. The International System for Protecting Rights During States of Emergency: University of Pennsylvania Press, 1994.

19 See Articles 2,3,4(1) and 7.

20 See Articles 3,4,5,6,9,12,17,18,19,20 and 23. 
thought, conscience and religion and the prohibition of torture, slavery, retroactivity of criminal legislation and imprisonment on grounds solely of inability to fulfil contractual obligations. ${ }^{21}$ However, the African Charter on Human and People's Rights contains no specific derogation clauses and the European Social Charter (Art. 30) which allows derogations does not specify non-derogable rights.

The discussion of "derogability" of some rights shows again the clash between ideal theory and real legitimized practice. The term "absolute" can be determined in the other way i.e. through the practicability of human rights norms, which is one of the features of the nature of human rights according to Macfarlane ${ }^{22}$. Human rights claims can never be made to what is physically impossible (to live forever). The assertion has been used often as an argument against the whole idea of social and economic rights. The rule here is that what the individual can have a right to is what their own civil society, as at present organized, can provide for all its inhabitants; since even to meet the minimum basic needs of the population may require substantial changes in its established institutions and practices. So, practicability has rather to be established in terms of the probability that proposed changes will help meet the basic economic and social needs.

\section{Evolution through interpretation}

Human rights are set out in a multitude of conventions that are regional or global, specific or general. The rights in conventions are not static but all conventions evolve through interpretation. The European Convention of Human Rights (ECHR) is perhaps the most interesting convention to study as an example of the evolution through interpretation, as it has an elaborate system for its implementation through the individual right to bring cases to the European Court of Human Rights (ECtHR). This has entailed a vast jurisprudence that is easy the read and get an overview of, to see the evolution of rights. Although the ECtHR recognises that there are limitations on what can be done through interpretation, in some circumstances the application of the Convention has lead to quite new rights being included under the relatively general headings of the Convention. Ovey and White mention how rights of transsexuals to recognition of their gender identity has been interpreted to be included under Article 8 on the rights to respect for private and family life, even if this right is not mentioned in any travaux preparatoires and it would not have been a right recognised in the member states when the Convention was drafted and thus presumably not in the minds of those drafting the Convention. Such dynamic interpretation may be necessary to protect individuals in a comprehensive manner if the Convention

21 See Articles 6,7,8,(1)(2),11,15,16 and 18.

22 L. J. Macfarlane, The Theory and Practice of Human Rights: Maurice Temple Smith, London, 1985, pp.9-11.

(C) Palacký University Olomouc, Czech Republic, 2012.

ISSN 1213-8770 (print), ISSN: 2464-6601 (online). 
is not to lose its actuality. ${ }^{23}$ Ovey and White find the rights of transsexuals as a very good example of the interpretation of the ECHR as a living instrument and the development of positive obligations for Member States. ${ }^{24}$

As the discussion on human rights is politically attractive and various groups bring up issues of rights, there is a danger that there will be a fashion in human rights. Some rights are more attractive for the general debate than others, without this necessarily reflecting the seriousness of the right. For example, the right to a fair trial (like in Article 6 in the ECHR) is a very essential right, as is also reflected in the ECtHR jurisprudence. At the same time, in the general debate this may not be the most illustrated right. When certain issues attract a lot of attention in society for whatever more or less political reasons, the rights discourse may focus exceedingly on certain rights. This has been seen recently with the focus on integration of ethnic minorities, where the debate has focused on social and economic rights (why do immigrants not work?) or with the debate on gay marriage or other rights for homosexuals. These are two separate examples but have in common that they show how when a question becomes attractive in the debate, the issue may also be brought forward as a human rights issue with an over-emphasis on a particular right, perhaps without this really being as central as such emphasis appears to indicate. Another way to formulate this is that the specific situation is over-emphasised instead of focusing on what core rights lies behind the problems witnessed - namely the violation of a right to equal treatment and the possibility for some groups (like sexual minorities) to enjoy human rights accorded to all. There are recent examples of how politicians realise the complexity of implementing social policy via human rights canons and for example focus on commitment to standards rather than rights as such. Such an example is the debate on homosexual marriage in the United States where there is a refocus on common grounds in specific standards rather than basic rights and where proponents of this claim it is a radical way of changing the approach. ${ }^{25}$

\section{Inflation of rights}

There is a certain tendency all over the world to refer to all sorts of things as human rights. There is a danger in this, that it may lead to inflation of what really is the core content of human rights. It may be nice to have a right to compensation if public transport runs late or a right to decent housing, but these are not human rights. If the concept is diluted and the terms used vaguely, the real rights may become weakened. In democratic and developed states, what is seen is the mentioned tendency to confuse human rights with citizen's rights to good ser-

23 Ovey \& White, op.cit., p 47.

24 Ovey \& White, op.cit., p 274.

25 See A. Madhani «Supporters of gay marriage are reframing the question» USA Today, November 11-13, 2011 
vice or the rights of citizens and businesses to efficient administration. In states with a lack of proper human rights protection, the issue may instead be a masking of real concerns behind exaggerated emphasis on matters of civic importance but that are not human rights as such.

Human rights have their origin in the rights of individuals against the state. The core of human rights should still be this. With the extension of this to include for example such matters as Drittwirkung with the protection of human rights by states really a way to protect some citizens against others, this core relationship of those that have the rights and against whom they should enforce them is not always clear. In trying to maintain the universality and core importance of human rights, one of the elements is to see that "real" human rights are those of individuals toward the state. This is also a way to counteract the inflation in rights: many rights toward other parties are mentioned as human rights but the idea of the main declarations is that rights between all sorts of other parties are not human rights in the meaning of the conventions.

At the same time it is more and more accepted that most human rights instruments to be effective must also include the understanding that in many instances the state must ensure that human rights are protected not just against actions by the state but against violations by other parties - states must take steps to ensure that rights are not violated whether that means not violating them themselves or not allowing anyone to violate them - otherwise put, having a positive obligation to ensure rights. If for example Article 8 of the ECHR is seen to include rights of transsexuals to recognition of their identity, there must be positive action taken to ensure this. ${ }^{26}$

It is hard to see that Drittwirkung could be ignored as that would leave many rights hanging in the air. At the same time, such effect may also often mean that there is a dilution of the core of rights as understood in their traditional sense: a protection of the individual against the state. Suddenly instead the border line to policy will be unclear.

\section{Cultural relativism versus universal human rights}

The main question here is: Are the moral and legal norms embodied in the contemporary doctrine of human rights merely the culture-bound creations of specific societies in particular historical periods, or can this moral standard be regarded as possessing an authority and universality that enables it to be applied and enforced against contemporary societies possessing different moral norms and values?

It appears as if the usual proponents of human rights, European states and to some extent North America as well as various NGOs, have become some-

26 Overy \& White, op.cit., pp 51-52.

(c) Palacký University Olomouc, Czech Republic, 2012.

ISSN 1213-8770 (print), ISSN: 2464-6601 (online). 
what cautious of proclaiming their universality. The human rights community is divided on to what extent the cultural context should be considered and determine the rights. ${ }^{27}$ This caution is not necessarily justified. As Winston has pointed out: "The fact that the bicycle was first invented in Scotland, does not imply that the bicycle cannot be used in China. ${ }^{28}$ By Meron ${ }^{29}$, if the idea of rights is modern and Western, the values inherent in the conception of human rights and in the particular rights that have been recognized are not Western. That a human being ought to live, should not suffer torture, arbitrary detention etc., is not an idea exclusive to the West.

Cultural relativism with rights applied as it fits the cultural and religious sensitivities of each country, is inherently and inevitably a complicated matter. If evidently culture, history and religion cannot be ignored, if these factors are given too much emphasis the entire idea of universal human rights holds no future. Human rights should be as neutral as possible, so that they can apply in different contexts and cultures. This by necessity means that the rights cannot be too specific but a core needs to be determined that can be accepted in different cultural contexts. The right as such should remain and not be diluted so it can be expressed so that the answer to whether there should be cultural relativism is no, but the answer to whether there should be adaptation to cultural conditions is yes.

In the centre is one right, the one and the same - around it is the specific environment of the conditions it needs to apply in. Democratic states respecting the rule of law may be able to cope well with certain "inflation" and granting more and more varied rights, but for the very states that have most problems with offering human rights protection to their citizens, it may be easier for others to demand this and for states to actually fulfil this, if the rights in question are the core of the most basic and universal rights. ${ }^{30}$

If rights are made too specific, if they "go too far" the consequence may be that they lose their universality. This is not to argue to apply rights on a common lowest denominator, but that the core right should be general rather than specific and to some extent perhaps actually reflect the lowest common denominator but not in the negative sense but as the very core, the central element of the right - its real subject matter. If that core, the very thing that can be fought for and vigorously protected regardless of cultural relativism is diluted or diminished the idea of a universal protection of rights loses any meaning. To clean a right from its cultural outer cover does not mean to lessen the right, quite the contrary.

27 The Economist, op.cit.

28 M. E. Winston, Philosophical Conceptions of Human Rights: International Institute of Human Rights, Strasbourg 1994, p.15.

29 T. Meron, Human rights in international Law: Legal and Policy Issues: Clarendon Press, 1989, p. 29.

30 The thought inspired by Masters' student Monika Silvet. 
Rights of women or rights of sexual minorities may be good examples of areas where the universality of rights cannot be maintained in different cultures if the rights are interpreted in a more detailed manner, as there are wide differences in opinion about the substance of such rights.

Rule of law and abiding by laws is part of culture and affected by culture. As Krygier says, rule of law cannot be built upon every person all the time making calculations whether to abide by laws or not. It must be part of society, part of culture. At the same time, abiding by laws and rules is affected by culture. Strong institutions often follow from traditions in which they were formed. Traditions and expectations make institutions meaningful and have an invisible pervasiveness. At the same time, Krygier warns against exaggerating with culture. It may be used as an excuse for not tackling real problems. ${ }^{31}$

It is generally understood that human rights treaties differ from other international treaties in some respects, like that the meaning of the concepts set out as human rights although they do have an autonomous meaning also find their meaning from the laws of the states parties to the treaty. States have a margin of appreciation, social developments, culture and other factors must be taken into consideration if the treaties are to fulfil their objective. ${ }^{32}$

When the law at national level is in a transitional stage which is often the same time as when there are big differences between different states, it is hard to find common ground that an international human rights system can rely on. This leads to a wide margin of appreciation for example for the ECtHR. Parental rights of homosexual or transsexual persons is one such right where there is a quite recent development in many states but the level of development is rather different. $^{33}$

There are rights that do not exist in treaties of human rights, like the right to cultural respect. This is a very basis of other rights functioning and as such may work as a basis for other human rights. Maybe also such a right could ensure that other rights need not be seen relative to culture, as such application of core rights is itself a basic right.

Universality of (especially "new" or specified) human rights is an illusion in many cases and it has been proved by several researches such as one conducted by McNamara ${ }^{34}$. The author states that despite the claimed universality of human rights values, the controversies related to human rights implementation are not resolved universally. He makes a good example with the analysis

31 M. Krygier "Approaching the Rule of Law" in W. Mason (ed.), The Rule of Law in Afghanistan : Cambridge University Press, 2011,. pp 15-34

32 Ovey and White, op.cit., p 55.

33 Ovey and White, op.cit., p 236.

34 L. McNamara, Human Rights Controversies. The Impact of Legal Form: Routledge-Cavendish, 2007. 
of three recent controversies i.e. double jeopardy reform, same sex relationship issues and hate speech laws and suggests that the difference is caused by different technical decision making processes. It is also probably true that the legislative process, decision making in the member states has not been in the agenda of international bodies such as EU or the Council of Europe. The emphasis has always been material law; the means how to achieve the goals are left to the States. However, it seems that procedural aspects may play a greater role than expected. By Campell: "there is no accepted moral or legal method that can be utilized to give the requisite objectivity to the value choices inherent in human rights jurisprudence" ${ }^{35}$ It is remarkable that the author is convinced that "positivization of human rights increases their utility but compromises their moral status". ${ }^{36}$ Therefore, the fair democratic process that identifies the human rights must be established, involving addressees of the rights.

\section{Religion versus universal human rights}

Although no religion holds the monopoly on affecting human rights, the interrelationship between Islam and human rights is the most debated. Apart from political reasons for this, the fact that Islam contains a special legal system through the so called Sharia law, brings the issue to the forefront. The status of Sharia in Muslim countries (apart from the expressly secular ones like Turkey) is at the top of the substantive law hierarchy as an incontrovertible norm but the real impact is weakened by concurrent secular legislation. The impact of Sharia is mainly felt in family law (and inheritance). ${ }^{37}$

Abiad points out that Islam has in many cases had a positive effect on humanizing pre-Islamic Arabian laws, customs and norms. Despite this, in modern times Islamic norms in several cases are in a normative confrontation with contemporary human rights standards. This is seen in how Muslim countries interact with international human rights conventions. Although Abiad recognises that religious considerations have an influence on the application of human rights treaties in Muslim countries, she finds that this impact is often artificial. The considerations put forward based on Sharia may be more political and States "hide" behind Sharia if they are unwilling to adhere to international human rights instruments ${ }^{38}$ The excuse for human rights violations, that they are in fact expressions of valuable cultural traditions, is used not just by Muslim countries. ${ }^{39}$

35 T. Campell "Human Rights: A Culture of Controversy", Journal of Law and Society, Vol. 26, No. 1: Cardiff University, 1999, p 6.

36 Campbell, op.cit., p 6.

37 N.Abiad Sharia, Muslim States and Innternational Human Rights Treaty Obligations: A Comparative Study: Bristish Institute of International and Comparative Law, London, 2008, pp 51-52.

38 Abiad, op.cit.pp 57-59.

39 Here useful thoughts were given by Masters' student Annely Protten. 
When the UN GA Universal Declaration on Human Rights was adopted on 10 December 1948 of the then nine Muslim states members of the UN, eight (Egypt, Iran, Iraq, Afghanistan, Lebanon, Pakistan, Syria and Yemen) voted for the Treaty. Saudi Arabia abstained but so did non-Muslim countries like South Africa and the Communist bloc states. The Saudi representative explained the abstention by declaring that the Declaration reflected Western values and culture and was at variance with patterns of culture of Eastern states, notably as far as the Article on religious freedom was concerned (Article 18 including a right to change religion, which is against the Quran). The same problem existed for other Muslim states but they still felt they could vote in favour, perhaps as the Declaration is not a binding legal document. ${ }^{40}$

Another way in which the effect of Sharia is seen is that in relation to binding international law instruments Sharia is sometimes (and quite often) used as a motivation for making reservations. This has been criticised by objecting states (as well as scholars) not least because of the vague nature of Sharia itself which means that many reservations become vague and in some cases may be against the nature of the Treaty. Reservations that go against the nature and purpose of a Treaty are not seen as permitted in international law. It is a habitual practice for Muslim states to refer to Sharia in order to make reservations, without isolating and specifying the provisions of Sharia, meaning the specific Islamic norm that a treaty is in conflict with. ${ }^{41}$

If these are examples of how Sharia can be (ab)used by states in relation to international human rights norms, there are also examples from Muslim countries of how reforms can be made within the framework of Sharia. This includes reform of laws relating to the status of women in Egypt and Pakistan. Reasoning and traditional jurisprudential techniques from Sharia may allow modernising national law and in this process taking human rights into consideration. ${ }^{42}$ In conclusion, it may be said that Muslim states mainly have a poor record in implementing human rights treaties, but this cannot be blamed primarily on Sharia. ${ }^{43}$

\section{State Failure}

Paul Farmer identifies any human rights violation as "symptoms of deeper pathologies of power", linked to the social conditions that may determine "who will suffer abuse and who will be shielded from harm"44. For example, Amnesty International challenged world leaders to apologize for six decades of human rights failure. Furthermore, by Amnesty International "Injustice, inequality and

40 Abiad, op.cit., pp 60-61

41 Abiad, op.cit., pp 79-80

42 Abiad, op.cit., p 128.

43 Abiad, op.cit., p 175.

44 P. Farmer, Pathologies of Power. Health, Human Rights, and the new War of the Poor: University of California Press, 2005, p xiii 
impunity are the hallmarks of our world today" ${ }^{45}$. Wealthy and rich have, of course better possibilities to protect their rights. Sometimes, it seems that some of the social groups that cannot defend themselves sufficiently are not accepted by State power because of financial, political or other reasons. The syndrome of "our" and "other" is visible, for example in the case of suspects of terrorism, political dissidents. Quasi-official recognition (Merkel, Cameron, Sarkozy et. al.) of failure of so called multiculturalism also raised tensions between national groups (case of Roma children 2010 in France) and even created certain expectations that human rights violations can be accepted in the case of minorities.

However, what is relevant in the context of the multi-culturalism debate is that the message of European politicians to a large extent got distorted along the way, either accidentally or on purpose by people who are opposed to the current policies regarding immigration and tolerance of different cultures. The statements of Merkel, Cameron and others that actually discussed how the implementation of multiculturalism had failed were used to condemn minorities. The message European politicians tried to get across was that the application of multiculturalism has been such that it has encouraged segregation and that has resulted in the problematic and unenviable situation many European countries find themselves in these days. The conclusion should be that there is a need to be more inclusive regarding different minorities, not segregating them to particular areas and leaving them to fend for themselves. This does not mean the minorities from different cultures need totally assimilate but they need to be included in the mainstream society by education and social interaction. ${ }^{46}$ This debate is made more complex not just by distortion of the message by those who oppose open policies but also by an exaggerated political correctness, ${ }^{47}$ leading to a situation where real debate is difficult.

At the same time, there are serious social problems at issue, where the hand of the State in directing matters is not visible. There is increased solidarity with popular uprisings, where the igniting factor may often be violations of minority rights. Less protected groups cooperate or at least show solidarity. At the same time, recent London street protest show how the State is seriously considering taking away social guarantees as a punishment. Would this mean lessening the protection of rights of these groups? Also peaceful demonstrations start from the nervousness and fear within social groups about the potential violation of their human rights. The term "slutwalk" was for example coined when police officials, representatives of the state, claimed that to avoid sexual violence women should

45 Amnesty International Report 2008

46 In this section, the thoughts of Masters' student Rene Kullör are incorporated and much apprecaited.

47 Regarding which another Masters' student, Sandra Schreilechner brought up the example of the situation casued by the book by Theo Sarrazin, where what could be seen as attempts at a frank debate on immigration using provocation to get attention was not seen to be acceptable. 
dress modestly. This affects - albeit indirectly - freedom of expression and even the presumption of innocence.

Today the internet is more and more important as a tool to exercise rights and claim protection of rights. It is too easy to start petitions and make claims that are based only on emotions and that purport to offer alternatives to traditional justice. At the same time, there is clearly a tendency for people to feel that the traditional society (the State) does not protect them and they look for alternative means of expressing themselves. The question arises if in interpreting fundamental rights, democratic mechanisms should be taken into consideration to a greater extent?

Neil A. Engelhart suggests that responsibility to protect human rights has not only normative but also empirical dimension ${ }^{48}$ and the later cannot be handled by a State as nowadays, the absolute power of a State is certainly overestimated. Failure of State in protecting human rights may be caused by many factors such as corruption, political struggles, financial constraints, foreign political dependence or influence.

\section{Patching and repairing or getting new?}

There is a danger in starting from scratch to make new treaties, as it may be harder now to agree on rights than when for example the Universal Declaration or the UN conventions were made. Then the world consisted of considerably fewer states and these were more homogenous. To open up and start from the beginning may lead to an erosion of what has already been achieved. This is consequently not what we suggest, but what is needed is a re-evaluation and interpretation. The case law on human rights has proven very valuable but it has also highlighted changes and the need to give a new look.

The neutrality as well as universality and authority of rights is what can ensure that the effect and importance of universal human rights is preserved. Rights protect the individual against the state as well as ensure that the state protects the individual. This may mean a balance between individual values and social interest. Rights are interdependent and indivisible at least to a point.

48 N. A. Engelhart "State Capacity, State Failure, and Human Rights", Journal of Peace Research, Sage publications. 2009. 
As proposed by Renteln ${ }^{49}$ and many others, only through cross-cultural ${ }^{50}$ empirical research can discover values shared by all cultures. Relativism ${ }^{51}$ is consistent with the existence of cross-cultural universals. Even if there may be not a universal commitment to a certain value, a consensus could emerge with respect to that value. The universality of human rights requires respect for the diversity of faiths and cultures. Achieving universal acceptance of international human rights norms is a process. ${ }^{52}$ Thus, there should be elaborated a cross-cultural approach for validating human rights to find homeomorphic equivalents for human rights in all civilized cultures to avoid the charge of cultural imperialism. By this approach, human rights cannot be derived philosophically, but can only be established by empirical demonstration. ${ }^{53}$ Today, a consideration of various international human-rights instruments reveals that some of them do not embody universal values. So, one of the sharpest problems of human rights are those, stemming from ideological competition. The only progress in the field of "universality" is the substantially similar terms in regional treaties. ${ }^{54}$

\section{Some concluding remarks}

Basic human rights should be really basic, deriving from the essence of being human. This way they can be at the top of the pyramid and not be violated by other laws, national traditions or similar.

There has been inflation in human rights in the past decades, in the sense that more and more things are referred to as human rights by various interest

49 A. D. Renteln, International Human Rights, Universalism Versus Relativism : Sage Publications, 1990, pp. 9-15.

50 The term "culture" can be used here in its broadest sense as the "totality of values, institutions and forms of behaviour transmitted within a society. Thus, this wide conception of culture covers Weltanschauung (world view), ideologies and cognitive behaviour". See A. A. An-Na' im (ed.), Human Rights in Cross-Cultural Perspectives. A Quest for Consensus: University of Pennislyvania Press, Philadelphia 1992.

51 Accordig to Rorty, the claim of "cultural relativism" is named by those who indignantly reject it in reason, that such relativism seems to them incompatible with the fact that Western human rights culture is superior. See R. Rorty, "Human Rights, Rationality, and Sentimentality" in S.Shute \& S.Hurley (eds.), On Human Rights. The Oxford Amnesty Lectures 1993: BasicBooks, New York 1993, p.116.

52 As example General Assembly of the United Nations is representative of norm sender. The body of standards is Universal Declaration of Human Rights. Global and regional treaties are theoretically descriptive interpretations.

53 Going even further, R. J. Vincent proposes to have grounds in "practical anthropology" which may be justified as far as every research or startpoint wears the ideas of its creator. See: R.J. Vincent, Human Rights and International Relations: Cambridge University Press, 1986.

54 As Robertson and Merrills pointed out, the using of substantially similar terms (interpreted in similar way) as "criminal charge", "discrimination", etc., gives us reason to speak of the development of a truy international human rights law: A. H. Robertson, J.G. Merrills, Human Rights in the World: Manchester University Press, 1989, pp. 293-295.

\section{๑) Palacký University Olomouc, Czech Republic, 2012. ISSN 1213-8770 (print), ISSN: 2464-6601 (online).}


groups or politicians. It is also tempting - particularly in authoritarian states - to hide real human right problems behind discussions about other rights of a lesser nature, such as rights to good public services or similar. Citizens rights of various kinds should not be confused with human rights and human rights are rights of the individual against the state (or extensions of the state through Drittwirkung) and not various rights between private parties. If the lessening of the value of basic human rights is to be avoided, there is a need to get back to a more purist and universally accepted definition of what really are basic human rights and freedoms and how they should be protected. This determination may have to be quite general so as not to jeopardise the universality. ${ }^{55}$

This may appear as a resignation to using only the lowest common denominator, but to protect universality by sacrificing certain specifications of rights must not mean a step backwards. Rather, it may be seen as a needed recognition and tolerance of cultural differences. The essential function of human rights should be to protect individuals against the state. Everyone regardless of culture, social status, religion or where they live have certain inalienable rights just because we are all humans. This core of human rights must not be overshadowed by more specific rights to good service, good administration or protection of specific interests.

55 Especially the Masters' students Enni Kranni, Sandra Schreilechner and Dimitri Terjajev inspired the Concluding Remarks. 